\title{
Dialecto, norma, fronteras: Juan José Morosoli "traductor" y traducido por Sergio Faraco
}

Pablo Rocca ${ }^{1}$

\begin{abstract}
Resumo: Tornar inteligível uma expressão ou uma forma dialetal do sistema de certa língua, da qual hipoteticamente ela provém, exige um movimento duplo de validação de um segmento: por aproximação e por simultâneo distanciamento da norma. E muitas vezes essa nova forma expressiva acaba por se incorporar à norma. A literatura gauchesca e sua heterodoxa herança percorreram esse sinuoso caminho no Rio da Prata, primeiro, e no sul do Brasil, mais tarde, preservando o grande panorama do espanhol e do português muito mais do que em qualquer outra parte da América Latina. Juan José Morosoli (Minas, Uruguai, 1899-1957) se defrontou com o dilema de escrever uma literatura narrativa que fugiria dos esclerosados reflexos da tradição da gauchesca sem escapar à representação da fala e dos dialetismos próprios da sua região, consciente de que muitos pertenciam a esse acervo literário. Esse processo constitui uma primeira forma de tradução. Já no âmbito do português da fronteira sul, Sérgio Faraco (Alegrete, RS, 1940), ao traduzir alguns contos de Morosoli, depara-se com o mesmo problema em outro contexto de língua, em contato com o espanhol do sur. Um e outro exemplos mostram que o conflito entre dialeto e norma pode tornar-se uma luta cultural e estética.
\end{abstract}

Palavras-chave: Dialeto; Norma; Narrativa Sur-Sul.

Resumen: Para hacer inteligible una expresión o un giro dialectal del sistema de cierta lengua, de la que hipotéticamente procede, hay un movimiento de aproximación y una simultánea distancia de la norma. Esta, muchas veces, termina por incorporar la nueva forma expresiva. La literatura gauchesca y su heterodoxa herencia recorrió ese arduo camino, primero en el Río de la Plata, luego, en el sur de Brasil, manteniendo el gran cuadro del español o del portugués más que en cualquier otra parte de América Latina. Juan José Morosoli (Minas, Uruguay, 1899-1957) se enfrentó ante el dilema de hacer una narrativa que escapara a los duros reflejos de la tradición de la gauchesca sin rehuir la representación del habla y, en consecuencia, los dialectismos propios de su región, consciente de que muchos venían de ese acervo literario. Así, tal proceso constituye una primera forma de la traducción. Desde el portugués de la frontera sul, Sérgio Faraco (Alegrete, RS, 1940) al traducir el español de un puñado de cuentos de Morosoli se encontró con el mismo problema en otro contexto de lengua, en contacto con el español del sur. En uno y otro caso el conflicto entre dialecto y norma puede volverse una lucha cultural y estética.

Palabras-clave: Dialecto; Norma; Narrativa Sur-Sul.

1 Profesor Titular de Literatura Uruguaya - Departamento de Literaturas Uruguaya y Latinoamericana de la Facultad de Humanidades y Ciencias de la Educación. Universidad de la República de Uruguay. 


\section{Introducción}

"La poesía es una abstracción y el cuento una experiencia referida y no otra cosa. Una experiencia del conocimiento del hombre, con medio ambiente - es decir clima psicológico, clima moral y social". El dictamen, emitido en 1945, pertenece a Juan José Morosoli (Minas 1899-1957), quien por entonces ya tenía una obra consolidada en el género. Como su literatura se apoya en seres de este mundo, en su opinión el narrador viene a ser un intérprete e interlocutor válido de los "procesos mentales" de quienes apenas pueden mostrar "por sí mismos las dimensiones de su espíritu" (Morosoli, "Cómo escribo mis cuentos”, 1971: 100). Visto así, el escritor sería casi un médium de quienes sólo tienen voz para la comunicación cotidiana, a quienes pide prestadas sus palabras para trascenderlas, para hacerlas literatura, de quienes saca - para salvarlos, reinventándolos - gestos y siluetas que se perpetúan en $s u$ lenguaje, salpicado por el de ellos.

En el siglo XIX y un poco más allá la novela, género privilegiado, fue "el sistema de la lengua" (Bajtín, 1989: 80), el gran almacén de las palabras que representaban todo tipo de cosas. El cuento, en cambio, en su brevedad, se asomaba como un recorte más ceñido, menos "social", reducido a un episodio, renuente a la descripción demorada. Por lo mismo cada término debía ser medido con cuidado, mucho más cuando se desviara de la norma lingüística estándar de una lengua o cuando acudiera a formas dialectales, ya que tenía que aportar algo especialmente significativo de esa "experiencia referida". O callar.

Hacia 1930 el cuento era un género en formación. En lengua española aún no había conquistado el prestigio que obtendría con las historias ya escritas por Horacio Quiroga y, pronto, por Borges, pero acumulaba piezas significativas. Basta pensar en el superlativo elogio de Poe, Maupassant, Kipling y Chejov que hace Quiroga en el primer punto de su "Decálogo del perfecto cuentista", publicado originalmente en julio de 1927, cuando pide creer "como en Dios mismo". Esta sentencia hiperbólica habla del doble estado de existencia plena del género y de la convalecencia de su recepción (Rocca, 2006). En su línea, algunos narradores hispanoamericanos empezaron a especular sobre esta forma; entre ellos Morosoli fue de los más constantes. ${ }^{2}$

Contra las apariencias, que la propiedad básica del cuento sea la de referir una experiencia que equilibra la ecuación palabra y mundo. Estamos, así, ante el nudo de la cuestión no sólo en la narrativa de Morosoli sino en gran parte de la literatura y el arte de su tiempo (dentro o fuera de América), porque para 1930 las vanguardias habían atacado gravemente el problema de la representación en cuanto tal. La carga de la prueba se podía poner en la manera de referir - o sea, en el lenguaje y sus artificios- más que en la pura

2 La palmaria o encubierta poética que se acumula en las superpuestas capas de sus muchos artículos y conferencias sólo se hizo visible cuando, bastante después de su muerte, se los recogió parcialmente en libro (Morosoli, 1971; 1999). Algunos pocos textos de esta naturaleza, incluso, aún permanecen inéditos, resguardados en el archivo de Juan José Morosoli. En su gran mayoría, la colección documental de Morosoli se encuentra en la Sección de Archivo y Documentación del Instituto de Letras (SADIL), Facultad de Humanidades y Ciencias de la Educación (Universidad de la República), al que lo incorporamos en 1999, en el preciso momento en que fundamos este acervo, denominado en sus comienzos Programa de Documentación en Literaturas Uruguaya y Latinoamericana. La incorporación de este valioso conjunto fue posible por generosa donación de las hijas del autor (Mary y Ana María Morosoli), y por la mediación de nuestro inolvidable amigo el Prof. Heber Raviolo (1932-2013). Algunos papeles del autor se resguardan en la Biblioteca Nacional (Montevideo) y parte de su biblioteca particular, sobre todo la de autores uruguayos, se encuentra en la Casa de la Cultura del Departamento de Lavalleja, Minas. 
enumeración de la "experiencia", sorteando el encierro en la colección de historias chicas, de alcance puramente anecdótico o circunstancial.

Cualquiera que haya leído así sea un par de historias de Morosoli, aun si a priori desconoce el medio representado, advierte que en esas narraciones se recuperan las vivencias de seres y situaciones de su pequeña ciudad serrana, Minas, y de sus alrededores cubiertos de campos pedregosos, en chacras más que en estancias o en la soledad de la sierra. Ciertos personajes (como el calagualero, el arenero o el monteador) o algunas pinceladas del paisaje agreste -pero nunca su descripción minuciosa o abrumadora- son índices contextuales inconfundibles de esas historias. En algunos casos (como en el relato "Los albañiles de «Los Tapes»", 1936), el ambiente tiene un mayor grado de protagonismo, aunque menos fuerza del que puede tener la atmósfera misionera en los cuentos de Los desterrados. Tipos de ambiente (1926), de Quiroga. Muchísimo menos valor en sí tiene el medio del que le asigna Javier de Viana (1868-1926) en sus cuentos atravesados por la idea de ligar el sujeto a su indumentaria y al paisaje de un campo que se sucede sin aparente fin. Morosoli se separa del principio determinista que liga personaje y ambiente, asociación impuesta por el realismo - o, mejor, por el positivismo filosófico- que, sólo entonces mansamente empieza a declinar en su versión naturalista. La transición es ostensible si se comparan los títulos de sus pocas colecciones de cuentos con los muchos de Javier de Viana, el más prolífico, influyente y tal vez el mayor cuentista criollo rioplatense. Entre 1896 y 1919 Viana titula sus libros Campo, Abrojos, Yuyos, Leña seca, Cardos, Macachines o utiliza en otros paratextos sustantivos que son rioplatenismos (Gurí, Gaucha). En cambio, salvo en una ocasión (en el volumen Los albañiles de "Los Tapes"), Morosoli elige categorías fuera del tiempo y de un lugar concreto para sus títulos: Hombres, Hombres y mujeres, Vivientes, Tierra y tiempo. No en vano evalúa en varios de sus artículos y conferencias la obra de Viana tratando de ubicarlo, respetuosamente, como el retratista de un tiempo pasado, el tiempo gaucho, en contraste con su proyecto que atañe al campesino - con o sin patrón- de la serranía.

El cuento que se escribía en diferentes rincones de América Latina gozaba de un auditorio de relativo alcance en las publicaciones periódicas de circulación masiva. Para algunas de ellas (Revista Multicolor de los Sábados del diario Crítica, Buenos Aires; Suplemento Dominical de El Día, Montevideo) Morosoli destinó la mayor parte de sus ficciones y hasta de sus artículos. Mientras las grandes figuras del siglo XIX seguían gozando de desigual reputación (Flaubert, Zola, Dostoievski), al tiempo que los textos de "vanguardia" empezaban a ser paladeados por algo más que los pequeños círculos (Joyce, William Faulkner, Virginia Woolf), en la literatura latinoamericana se agitaba el gran fantasma del pintoresquismo. El color local aparecía como trauma o despuntaba como mal de origen para la literatura americana, marca subsidiaria de la matriz europea de la que trataba de diferenciarse, pero por diferentes medios recaía en la atracción poderosa de las propuestas técnicas imaginadas en otros espacios para otros escenarios. Varios tormentos agitaron los ánimos de autores y críticos: cómo transformarse en un escritor fuera de la estima de los más inmediatos congéneres; cómo conquistar un amplio abanico de lectores dentro y fuera de la lengua española; cómo evitar las exigencias del gusto de los mercados centrales que asignaban a la literatura americana un libreto fijo -si es que algo le asignaban-, el de escribir sobre lo local con una fuerte dosis de exotismo.

Un par de ejemplos tal vez clarifiquen estos dilemas. La novela sobre la revolución mexicana, que inauguró Mariano Azuela en el apogeo mismo de esta larga y tortuosa lucha, es apropiada por la industria del cine norteamericano en versiones ahítas de tiros, co- 
ros de gritos agudos, imágenes de campesinos indolentes echados al sol con la protección dudosa de un gran sombrero de enormes alas cerca de la proximidad de tunas demasiado espinosas. Idéntico destino típico y hasta más pasteurizado tuvo Doña Bárbara, de Rómulo Gallegos, novela de buena circulación americana ya que no es raro, aún hoy, toparse en librerías de viejo de Montevideo con su primera edición de Barcelona (Araluce, 1929) o más fácilmente con sus múltiples reimpresiones por el mismo sello. Esta ficción desafió los cánones del regionalismo e hizo su camino de prestigio entre los escritores americanos; pudo atraer un público pero, gracias a la versión hollywoodense de 1943, pasó a ser un icono del remotismo semitropical. La actuación protagónica de María Félix y Julián Soler consagró una mirada en que vida y naturaleza se funden en un destino, solitario y algo cursi. El proceso siguió su caída en las versiones contemporáneas del texto para teleteatros de enorme difusión hispanoamericana. Visto de este modo, el cuento fue una reacción contra la visión totalizadora de la novela realista pero también contra la industria del cine hollywoodense que, hasta entonces, sólo había menospreciado (o encorsetado) la imaginación americana.

\section{Morosoli, el cuento y el dialecto rioplatense}

Sólo como agradable sueño Morosoli se pudo figurar que alguno de sus textos fuera llevado al cine -lo cual feliz y eficazmente sucedió casi medio siglo después de su muerte-; ${ }^{3}$ como pesadilla debió temer para sus historias un destino semejante al de Doña Bárbara. Sabía bien que para escapar del catálogo costumbrista había que reflexionar sobre la escritura, había que leer y pensar la literatura de su tiempo y aquella que lo precedía, de lo que sus textos críticos y sus notas dan floreciente prueba. De ahí, también, que lo rondara habitualmente cierta obsesión por delimitar el microuniverso narrativo que representaba, algo que pudo entenderse como vocación por fijar en la escritura la vida del terruño. En 1953 en la conferencia "La novela nacional y alguno de sus problemas actuales" Morosoli acude al plural de modestia para evaluar su trabajo en el panorama de la narrativa uruguaya: "Cuando nosotros llegamos terminaba el ciclo que contenía todo lo que la novelística de la época consideraba imprescindible para escribir una buena novela nacional. Llegamos cuando transitaba del gaucho al campesino" (Morosoli, "La novela nacional...", 1971: 68). Ese pasaje, que caracteriza con agudo acierto, lo vincula a las posibilidades del realismo del que no se aparta, aunque lo cuestione en sus modalidades más crudas. A su vez, la diferencia entre gaucho y paisano, que en principio establece más como de tipo social y cultural ("Cuando el gaucho bajó del caballo dejó de ser novelable. Nosotros lo encontramos de a pie", art. cit.: 67) en rigor pone sobre el tapete el gran problema de la tradición literaria, que corresponde al primero, y el esfuerzo de novación verbal que se debía emprender con el segundo para atribuir sentido a su figura y sus lenguajes.

El gran desafío, que con el transcurso del tiempo se vuelve programa estético, se situaba en cómo hacer hablar a los sujetos populares del área rural o suburbana que escoge para sus historias, esos seres de papel que partían de quienes podía conocer muy bien. Traspuestos a la escritura se volvían un problema añadido al dilema entre lo pintoresco y lo universal: qué hacer con lo dialectal y cómo barajar la tradición poderosa de la literatura gauchesca que había cristalizado ese dialecto como literatura amenazando la norma

3 Las más célebres y, quizá, las mejores logradas en los largometrajes Viento del Uruguay (Suiza-Uruguay, 1989, guión y dirección de Bruno Soldini) y El viaje hacia el mar (Uruguay, 2001, guión y dirección de Guillermo Casanova). 
-desde Hidalgo a Ascasubi, pasando por Lussich y Hernández-y, sobre todo, utilizando y realizando "en el grado más alto las posibilidades del sistema", según siempre lo hace la gran literatura (Coseriu, 1962: 99).

La poderosa invención de la gauchesca se había vuelto actividad rutinaria hacia 1920 . Por otro lado, se hacía sentir la coacción del casticismo de quienes promovían la inflexibilidad de la norma castellana como reacción - pocas palabras más justas para el caso- a la avalancha de la literatura regional. En 1926 el Seminario de Cultura y Lenguas Románicas de la Universidad de Hamburgo publicó Das ausländische Sprachgut im Spanichen der Río de la Plata. Ein Beitrag zum Problem der argentinichen Nationalsprache, de Rudolf Grossman. Puesto que fue escrita en alemán, y se editó en formato de tesis universitaria, esta investigación se aseguró un prolongado olvido. Hubo que esperar a 2008 para que la traducción de Juan Ennis nos revelara este voluminoso libro con el título El patrimonio lingüístico extranjero en el español del Río de la Plata. Por esa traducción sabemos de la aventura de vida e investigación de Grossman en fuentes argentinas y uruguayas (sobre todo las segundas); sabemos de su posterior radicación en el país de sus padres, donde reunió sus cientos de notas y las convirtió en una germánica tesis sobre un territorio, una lengua y sus variantes en diálogo con un amplio repertorio de fuentes literarias que conocía de primera mano. Detengámonos, apenas, en dos anotaciones de esta obra que sirven de diagnóstico del momento mismo que aborda Grossman, el tiempo de la formación y los primeros tanteos literarios de Juan José Morosoli. La primera refiere a la lengua hegemónica en los medios que monopolizan la escritura:

[...] la influencia del español castizo se ha vuelto en el presente de nuevo dominante. Los diarios más importantes de Buenos Aires: La Prensa, La Nación, La Razón, también grandes periódicos provinciales como La Capital en Rosario escriben un estilo ejemplarmente puro. Algunos, como La Prensa, han puesto incluso un rincón lingüístico con fines puristas, y como la prensa argentina [...] ejerce una influencia pedagógica omnipotente en el espacio público, mucho mayor que la del libro, su español es para un porcentaje muy alto de los lectores el único patrón modélico (Grossman, 2008: 112-113).

El segundo aserto tiene que ver con la relación entre el español y otras lenguas en el momento decisivo en que, como nunca antes, prosperan las traducciones en Argentina que pueden expandirse luego por los libros y, en una u otra modalidad, por los países vecinos:

$[\ldots]$ cuando $[\ldots]$ el diario recibe los manuscritos originales en otra lengua, se procura una traducción absolutamente modélica. En las redacciones de los mencionados periódicos, toda una serie de renombrados literatos españoles y locales [...] se preocupan por mantener la mencionada parte del diario en una altura lingüística digna de envidia (Grossman, 2008: 113-114).

Siempre que esta evaluación del investigador teuto-argentino fuera cierta hacer periodismo y literatura en Argentina, hacia 1926, alterando la norma hispánica continuaba siendo una empresa temeraria. Con todo, y como en ninguna otra zona americana, en Argentina se contaba con la tradición ferozmente crítica de una lengua nacional sometida a los cánones castellanos que, tempranamente, había tenido en Sarmiento a su más brillante expositor y al más encendido apologista de la traducción como método para modernizar el espíritu y la letra americanas. ${ }^{4}$ Como toda reacción produce su contrario, el hispanismo

4 En el exilio, Sarmiento preparó un informe que leyó en la Facultad de Humanidades de Santiago de Chile, el 17 de octubre de 1843. En esa pieza apostrofa: “¿Qué es hoy el idioma español? Es por excelencia el idioma 
y el pensamiento conservador fue (y es) en Argentina mucho más fuerte de lo que pudo ser o es del otro lado del Plata. Siempre que el diagnóstico de Grossman fuera correcto, el imperio castizo habría recaído sobre el periodismo y la cátedra. Ese dominio explicaría mejor la violenta reacción de los jóvenes martinfierristas argentinos en 1927 contra la propuesta de Guillermo de Torre por fijar en Madrid el "meridiano intelectual de Hispanoamérica" (Alemany, 1998). Ese sería, pues, el clima y las condiciones de producción de una literatura en cuyo seno continuaba la lucha entre sistema, norma y habla, entre tradiciones y renovaciones culturales y lenguajes. Ningún mejor ambiente que la discusión sin concesiones para abastecer una gran literatura.

Una cosa era enfrentarse a esa posición dominante desde los periódicos más o menos de izquierda y más o menos de avant-garde (Proa, Martín Fierro, Claridad) algo que, cada cual a su manera, hacían Borges y Arlt, entre otros escritores menos prospectivamente ilustres- o desde ediciones semiclandestinas, tanto porque las había selectas como de pobre factura y dudosa circulación; otra cosa muy distinta era combatir esa política hispanófila en los propios medios de prensa que defendían oficialmente esa postura. Habría que evaluar si en la orilla oriental del Plata la prensa tenía esa misma política lingüística, aspecto que desborda las posibilidades de este artículo, pero una revisión del mencionado suplemento de El Día, en el que Morosoli dio a conocer muchos de sus relatos y artículos desde mediados de los treintas hasta el final de su vida nos hace sospechar que, por lo menos en este muy difundido suplemento, la defensa de la "pureza del idioma" no era la regla áurea.

Si convenimos en que una lengua es un sistema compuesto por "lenguas individuales, todas diferentes entre si', un conjunto heterogéneo al que se llama idiolectos, entonces -como polémicamente lo expusiera José Pedro Rona-, no existió un solo lenguaje hablado "típico del gaucho", pero sí, en cambio, "el lenguaje gaucho en cuanto complejo de idiolectos individuales sumamente diversificados entre si"' (Rona, 2014: 28, 342). La gauchesca, nacida hacia 1815, se había vuelto práctica literaria continua en la que cada autor aportó su idiolecto echando mano a una reserva dialectal que, gracias al retorno de la lectura y sobre todo de la recitación en voz alta ante varios auditores, contribuyó a legitimar y hasta a codificar. Este sistema gozaba ya de más de un siglo de persistencia cuando Morosoli publicó su primer libro de cuentos, Hombres (1932). Para un novel escritor del interior era difícil esquivar al peso de esa tradición o, mejor, de la práctica de esa lengua literaria sobre el gaucho que se yuxtaponía a las voces que Morosoli podía escuchar o conocer por algunos segmentos del idiolecto de Minas y sus alrededores.

Varias veces se ha advertido sobre las marcas de oralidad y las soluciones de escritura gauchesca en Morosoli sin que estas hayan sido estudiadas con el cuidado que merecen. El primero en señalarlas fue Heber Raviolo, el gran editor y crítico de Morosoli, a quien debemos su cabal recuperación desde 1962 cuando publicó un pequeño tomo con inéditos en libro (El viaje hacia el mar. Montevideo, Banda Oriental), primer paso de un largo recorrido editorial. En una introducción a Hombres, tal vez contagiado él mismo de los

de traducir, y la célebre jeremíada de Larra "lloremos y traduzcamos", es la expresión más lacónica de la sentencia a que condenaron al pensamiento español los temerarios que se encargaron en otro tiempo de hacerse una civilización aparte cada vez que un español se resuelva a pensar, una vez secreta le ha de decir: hace doscientos años que ya se pensó eso, traducid, pues, y dejaos de pretensiones; habéis venido tarde". Y, más adelante, agrega: "La España no posee un solo escritor que pueda educarnos, ni tiene libros que nos sean útiles. Este es el punto capital. En nuestras escuelas, como en las de España, está adoptado el catecismo de Astete, que es traducido del francés; el de Poussi, que lo es igualmente [...] Los libros adecuados para proporcionar lecturas agradables e instructoras a la juventud son igualmente traducidos" (Sarmiento, 1949: 12 у 38). 
temores o prejuicios del narrador, Raviolo señaló que la proliferación coloquial produjo una "especie de desbordamiento de giros y expresiones populares que, sobrepasando los diálogos, se instalan en todo el relato" (Raviolo in Morosoli, Cuentos completos, 2009: 111). Esto no es más que la presencia de un narrador homodiegético, que no frena con su voz el gran repertorio de coloquialismos. La abundancia de estos "giros y expresiones" le hizo pensar a Raviolo que Morosoli había incurrido en errores de transcripción de formas dialectales, fallas que atribuyó a su impericia en el traspaso a la escritura de la reproducción fonética y gráfica o la impericia de los editores rústicos de Morosoli en la primera hora. Podría conjeturarse que Morosoli pasó por una transformación en la idea misma de literatura y en las formas de representación de la oralidad.

En los primeros libros, tanto en Hombres como en Los albañiles de "Los Tapes", Morosoli ensaya, duda y con bastante ortodoxia acaba doblegándose al régimen de la gauchesca, del que más tarde, hacia fines de la década del cuarenta, consigue zafar con un discurso más austero que acompaña la economía verbal de sus personajes. Pero hasta 1935 (ya que Los albañiles..., dice el colofón del libro, salió de imprenta el 7 de enero del 36) en la tradición de la gauchesca y, sobre todo, en la línea del cuento criollo a lo Viana, ese discurso hace el doble juego simultáneo de introducir la tipicidad y, de golpe, salir de ella. Como era habitual, el narrador sitúa entre comillas las palabras que se apartan de la norma para separar su lenguaje del que manejan los personajes, pero la sola mención de ese repertorio lo hace quedarse con parte del mismo. Dos ejemplos ilustrarán mejor estos movimientos. En el cuento "Los tres compañeros", escrito en 1935, aparece el siguiente diálogo y la acotación ulterior del narrador:

-Serán iguale todo los pagos... Pero pal que va por dir, están bien...

-Pero hermano, vos ve que nu hemos pasao ningún trabajo... ¿Si no pasamu algo q’vamo a contar?...

-Todo caso noj hacemo contrabandista...

-Taría legal...

Pasaron tres o cuatro noches durmiendo a "lo pampa". Desdeñaban quedarse en "las casas", adonde iban por carne (Morosoli, "Los tres compañeros", 1936: 93).

Comparado este diálogo con el de otros dos seres imaginados, que casi no tienen diferencia de clase social ni de registro cultural, pero que pertenecen a la etapa final de su obra, las diferencias son muy marcadas en la representación de la supuesta oralidad popular. ${ }^{5}$ Se trata de un par de personajes de "Un soldado", Tertuliano y Toledo, cuento publicado originalmente en El Día el 6 de setiembre de 1953 y reunido en el libro póstumo Tierra y tiempo:

-¡Dejesé! ¿Reventar trabajando entre abrojos y chanchos! ¡Ver acostarse las estrellas arando de tanto talón rajao!... ¡Si sabré lo que es eso!

-iParece mentira Tertuliano -contestó Toledo amablemente- que usted diga eso. Trabajo, es cierto. Se trabaja... ¿Pero qué me dice del invierno? Terminó de plantar el trigo y el trigo viene... Carneó dos chanchos... Empieza a llover y el rancho queda aislado... Usted

5 Ese "taría legal" es evidente lusitanismo (por el "ta legal") que aún es de uso cotidiano en gran parte de Brasil y que en los últimos años se ha hecho muy frecuente en el español rioplatense entre las generaciones más nuevas. Francisco Álvez me hace saber que ha escuchado en Uruguay varias veces la frase "Todo legal" y que hay un verso del músico e intérprete Fito Páez, de una canción de 2010, que dice "es una piba legal". En todo caso lo sorprendente es que la expresión haya llegado tan tempranamente al centro-sur uruguayo, Minas, un lugar de poco tránsito y bastante alejado de la cultura fronteriza. 
se come un guiso de porotos lleno de cosas de cerdo... Toma buen vino, después mate de café y al fin se acuesta a dormir... Y de noche otra vez... ¡Y que siga el tiempo nomás! [...] ¡Déjese de embromar! (Morosoli, Cuentos completos, 2009: 424).

Tertuliano vendría a representar un poco el personaje de la gauchesca y Toledo el campesino afincado. Aun así, a diferencia de lo acostumbrado en su primera época, en 1953 la escritura de Morosoli, salvo alguna marca diferencial, se aparta de los barbarismos, los idiotismos, las formas apocopadas, las contracciones y, sin embargo, preserva una expresión verosímil del habla del sujeto del topos que pretende representar. Los puntos suspensivos indican la vacilación o los silencios del hablante poco hábil en el manejo del discurso; las frases hechas (como "Parece mentira" o "Déjese de embromar") guardan ese sabor local sin necesidad de acudir, casi, a los americanismos. En la última de estas frases hechas, que combina resignación y fastidio, Toledo hace académicamente esdrújulo el verbo conjugado ("Déjese") que su interlocutor había pronunciado agudo ("Dejesé"), según se acostumbra en el área lingüística rioplatense. En el único original que disponemos de este texto tal frase interjectiva había sido sustituida por "¡Haga el favor!" (folio 2), que tiene el mismo significado que la definitiva, pero suena algo más solemne; la que por fin eligió habilita la diferencia en la acentuación del tiempo verbal, suficiente para dividir los campos culturales entre los dos hablantes.

En el curso de los años Morosoli tiende a aproximarse a la norma. Le importa el simulacro de la oralidad siempre y cuando triunfe la escritura académica y no, como antes, el residuo del idiolecto criollo que buscó reflejar en su sintaxis. Hay, también, una apuesta mucho más marcada hacia la densidad existencial de los comentarios de sus personajes. Como si Morosoli hubiera caído en la cuenta que la mimetización con la oralidad distrae la atención sobre lo que realmente importa: la naturaleza de los conflictos que se discuten, aunque estos se hacen siempre lacónicamente y a la manera del terruño. En otras palabras: decir poco para decir mucho. ${ }^{6}$

Al dar ese paso largo Morosoli se aleja del criollismo y se acerca a la narrativa que Antonio Candido llamará superregionalista, una literatura que aprovechando las tradiciones, los mitos, las costumbres y los lenguajes regionales se sobrepondrá a cualquier conciencia amena y despreocupada del atraso, superando el inconsciente o el "modo insospechado de ofrecer a la sensibilidad europea el exotismo que ella deseaba como distracción; y que así se vuelve forma aguda de dependencia en la independencia" (Candido, 1972: 349). En esta dirección podemos pensar en Morosoli como un precursor o -en el peor de los casos- como un ignorado coetáneo de Rulfo, quien en 1953 dio a conocer los cuentos de El llano en llamas, o del primer García Márquez, quien empezó a publicar sus ficciones hacia 1955. ${ }^{7}$ Por esos días Morosoli ha aprendido que la oralidad debe ser hasta cierto punto domesticada en la escritura. Y la escritura traduce la desvanecida oralidad, que sólo puede persistir si se hace literatura, que sólo valdrá si es revelación de

6 Debo esta observación última a la Mag. Gabriela Sosa San Martín, a quien agradezco la lectura de una primera versión de este trabajo.

7 Tanto Rulfo como García Márquez serán analizados por Candido como superregionalistas. Por cierto, el gran crítico brasileño desconoció la obra de Morosoli, pero no su amigo Ángel Rama, quien aparte de muchas referencias pasajeras escribió sobre dos de sus libros: "Juan José Morosoli, amigo de los vivientes", $E l$ País, Montevideo, 4/I/1958 [Sobre Vivientes] y "La retórica de un creador", Marcha, Montevideo, № 959, 15/V/1959 [Sobre Tierra y tiempo]. A pesar del enorme entusiasmo que el crítico uruguayo demostró por el concepto de superregionalismo y de su posterior reconversión en el de transculturación narrativa, Rama olvidó el caso Morosoli dentro de esas operaciones técnicas y culturales. Sobre el surgimiento y desarrollo de estas ideas véase la correspondencia entre los autores (Candido \& Rama, 2016). 
sí y del sujeto, no un costumbrismo atraído por la "baratija refranera" como dice en una de sus más célebres conferencias sobre literatura propia y ajena (Morosoli, "La soledad y la creación literaria", 1971: 58). Con ideas de este tipo, que había visto y admirado en otros, que había seguido con respeto y a la vez con prudente distancia en escritores de su región (como Erico Verissimo o Cyro Martins) la literatura de Morosoli -que no tiene semejantes estrictos del otro lado de la frontera- estaba fatalmente destinada a ser leída por Sérgio Faraco. Sólo tenía que descubrirlo.

\section{Morosoli por Faraco/ Faraco desde Morosoli}

Juan José Morosoli era, en 1991, un clásico uruguayo. Pero, como le sucedía a su amigo y coetáneo Francisco Espínola, por ejemplo, casi se lo ignoraba fuera del país. Ese año, en sociedad con editores privados, el Instituto Estadual do Livro de Rio Grande do Sul publicó en Porto Alegre una antología general de cuentos uruguayos (la primera de esta clase, que sepamos, en todo Brasil), preparada y traducida por los narradores Sérgio Faraco y Aldyr Garcia Schlee. También en 1991 salió una pequeña selección de nueve cuentos de Morosoli, de exclusiva traducción de Faraco, que tomó su título de uno de los cuentos que el autor no llegó a juntar en libro: "El largo viaje de placer", y al que sólo pudo conocer a través de una difundida selección de piezas narrativas del autor. ${ }^{8} \mathrm{El}$ volumen titulado A longa viagem de prazer fue reeditado varios años más tarde por otro sello de Porto Alegre sin cambio alguno (Morosoli, 1991, 2009). ${ }^{9}$ El cuento epónimo se incluyó en la antología colectiva que Sergio Faraco preparó con su colega. "A longa viagem de prazer" pauta el primer paso de frontera sur/sul, porque el solo inevitable canje del masculino al femenino en el núcleo de la frase por el sustantivo (viaje/viagem) habla de las asimetrías y las complementariedades de las dos lenguas.

8 El relato fue publicado por primera vez en el Almanaque del Banco de Seguros del Estado de 1953. Recogido en libro en Cuentos escogidos, Juan José Morosoli. Montevideo, Ediciones de la Banda Oriental, 1964. (Selección, prólogo y notas de Heber Raviolo). Este volumen que toma cuentos de todas las colecciones publicadas por Morosoli más algunas piezas que dejó sueltas (como “El largo viaje de placer”) tuvo muchas reimpresiones en los años sesenta y setenta y hacia fines de la década siguiente por lo menos dos reediciones parciales, siempre con el mismo título. Puesto que antes de 1991 era el volumen más abarcador de la cuentística de Morosoli debió ser este el que leyó el escritor riograndense para realizar su breve antología, ya sea en su versión más extensa como la más abreviada. Por otra parte, los tomos sueltos de cada obra de Morosoli no eran fáciles de hallar siquiera para quien fatigara las librerías de viejo de Montevideo hacia 1990, tomando en cuenta que el gran plan de obras que llevó adelante Raviolo en sus Ediciones de la Banda Oriental entre 1967 y 1971 quedó trunco y, en adelante, sólo se reeditó algún libro aislado (la novela Muchachos, Tierra y tiempo).

El propio crítico y editor, quien prologó el volumen publicado en Porto Alegre -y quien, por lo tanto, pudo asesorar a Faraco y obviamente conoció la colección antes de que fuera a la imprenta-, se encarga de darnos una pista y una orientación simultáneas sobre el uso del traductor de un volumen antológico y de sus preferencias por los textos de madurez, que eran también las suyas: "Com exceção de "O companheiro", pertencente ao seu primeiro livro de contos (Hombres, 1932), os demais são todos da sua maturidade criadora. "A longa viagem de prazer" e "A viagem até o mar" nunca foram publicados em livro pelo autor e apareceram em volumes póstumos. Os demais pertencem a Tierra y tiempo (1959) [...] preparado $e$ ordenado pouco antes de seu falecimento" (Raviolo in Morosoli, 1991: 19). Véase el detalle de los cuentos seleccionados en la próxima nota.

9 El volumen incluye los siguientes textos por este orden: "O burro" ("El burro"), "Um gaúcho" ("Un gaucho"), "Dois velhos" ("Dos viejos"), "O companheiro" ("El compañero"), "Solidão" ("Soledad"), "O aniversário" ("El cumpleaños”), “A longa viagem de prazer" ("El largo viaje de placer”), "O viúvo" ("El viudo"), "A viagem até o mar" ("El viaje hacia el mar").

Los textos para niños de Morosoli reunidos en Perico, con traducción de Charles Kiefer, fueron publicados en Porto Alegre por la Editora Mercado Aberto, sin data. El volumen contiene ilustraciones de Leonardo Menna Barreto Gomes. 
Sergio Faraco (Alegrete, 1940) se había instalado en la literatura gaúcha hacia fines de la década del ochenta como uno de sus más notables cuentistas. Había aprendido sobre todo de Hemingway -a quien, casi como al descuido, homenajea en su cuento "A dama do Bar Nevada"-, la concentración y la austeridad casi ruda en el decir. Su conocimiento de la obra y, más tarde, de la persona del cuentista uruguayo Mario Arregui (1917-1985) le permitió afirmar algunas ideas que ya venía cultivando acerca del cuento en un momento clave. Una correspondencia entre los dos escritores, mantenida en la primera mitad de la década del ochenta, es uno de los documentos más notables que contamos para pensar las distancias y aproximaciones de una literatura de frontera. Seguramente Faraco nunca había oído mencionar el nombre de Morosoli hasta entrar en diálogo con Arregui, aunque pudo reforzar la noticia sobre su calidad literaria a través de Julián Murguía, con quien mantendría una amistad muy fuerte después del exilio de este en Porto Alegre hacia 1982. Aunque Mario Arregui no fuera un promotor fervoroso de Morosoli -como sí lo era de Borges, Quiroga y Onetti-, lo recomienda a su traductor dentro de una amplia lista a tener en cuenta:

Además de la figura principal de Onetti, la literatura uruguaya contemporánea tiene nombres que mucho importan: Quiroga, Morosoli, Amorim, Espínola, Benedetti, José Pedro Díaz, Martínez Moreno... Para que tales excelentes escritores sean conocidos por el público brasileño sólo hacen falta, a mi juicio, buenos traductores y editores animosos (Arregui \& Faraco, 1990: 80).

En carta del 15 de abril de 1982 -ausente en la edición uruguaya- entre una detallada lista de once escritores compatriotas que sugiere publicar en Brasil, Arregui incluye en ese escalafón al escritor de Minas en el puesto número diez. Lo pone detrás de Quiroga, Onetti, Benedetti, Martínez Moreno, Amorim, Díaz (dos libros), Felisberto Hernández y Espínola (Arregui \& Faraco, 2009: 84). Significativamente, fuera de alguna pieza suelta de Onetti, Faraco no siguió el orden propuesto en sus trabajos de traducción y hasta no parece haber tenido empatía con la literatura de Benedetti, Díaz, Martínez Moreno ni Amorim -en cualquiera de los casos, salvo parcialmente el último, de asunto urbano o fantástico. En cambio, no cesó desde entonces de traducir historias de Quiroga; la relativamente cercana elección del décimo en la lista habla claro sobre su afinidad estética, porque una vez que el cuentista gaúcho leyó algunas historias de Morosoli no podía sino interesarse por ellas.

Faraco empezó a repensar su propia literatura a través de la traducción de la narrativa hispanoamericana vecina dentro de los cánones de representación ligados al realismo (es el autor de un solo cuento fantástico: “Um destino para o fundador"). La traducción, de esa forma, sería para el escritor -quizá para todo escritor que la ejerza- una especie ensimismada y autocrítica de la lectura, una proyección fantasmática de su proyecto de escritura, un laboratorio donde ensayar las posibilidades de las palabras y la sintaxis ajenas buscando las combinaciones ajustadas y hasta cierto grado propias. Al leer y traducir (es decir, leer en una segunda potencia) a sus contemporáneos Arregui, Guido Rodríguez Alcalá, Mempo Giardinelli, entre otros, así como a los precedentes Quiroga o Morosoli, la escritura de Faraco se afirmó en una tradición, en la que -como lo reitera en su canje epistolar con Arregui, quien recibe la propuesta con desconfianza- existe una comunidad cultural del sur en el territorio de la pampa más allá de las fronteras físicas y de las dos lenguas. Escribe Faraco el 23 de julio de 1981: “O Uruguai e o Rio Grande se parecem. O Rio Grande padece a influência deletéria do imperialismo cultural do centro do país e é nessa medida que teus contos recobram a índole do homem do campo - inclusive 
o rio-grandense - e, exagerando, sua "nacionalidade" (Arregui \& Faraco, 2009: 28). Responde Arregui en tajante posdata sin fecha: "Inobjetable lo de 'as peculiaridades do gaúcho', pero te diré que hoy estoy un poco de vuelta del criollismo, nativismo, telurismo o lo que sea. Ya hablaremos" (Arregui \& Faraco, 1990: 10). La traducción, desde este ángulo, oficia más como propósito político que como servicio cultural.

Sabemos de la importancia social de la traducción para el conocimiento de quienes no pueden leer en el original; sabemos de su fuerza divulgadora. En cambio, no se ha explorado tanto la posibilidad de conocer los textos de la propia lengua de partida desde las opciones de traducción a otra lengua intercomprensible, como el portugués, que a su vez tiene que lidiar con sus propios límites en cuanto los dialectismos de frontera le vienen del español del Río de la Plata y se acumulan en el archivo de una literatura con buenas aspiraciones de autoctonía para mediados del siglo XX. El caso es muy interesante a este respecto, sobre todo porque Morosoli -como se dijo- no es un escritor típicamente gauchesco sino que por el contrario avanzó hacia un progresivo apartamiento de ese código.

En unos meses de 1991, Faraco da a conocer en dos oportunidades su traducción de "El largo viaje de placer" (“A longa viagem de prazer") con algunas pocas diferencias entre sí. En las dos versiones lleva a los extremos la actividad procesal que Morosoli había hecho con sus obras, ya que se inclina a atenuar casi toda forma dialectal, eligiendo sólo algunas frases o expresiones equivalentes en portugués. En rigor, "El largo viaje de placer" es una historia que cae como un traje de medida para la estética de Faraco: diálogos de frases breves, economía de recursos verbales con singular capacidad expresiva, equilibrio entre lo local y lo exterior. Cualesquiera narraciones de Faraco, las de Noite de matar um homem o aun los cuentos urbanos de A dama do bar Nevada exhiben un involuntario aire de familia con el autor traducido (Faraco, 2011).

Concentrémonos, por esa doble comparecencia, en "El largo viaje de placer" sin olvidar otras traducciones de cuentos de Morosoli. El relato despliega una forma piadosa del humor y se construye principalmente en base a los personajes Tertuliano (otra vez el mismo nombre), quien ha ganado en una rifa un camión viejo y dialoga con Aniceto, más modesto que su compadre. Algo pudorosamente, el primero informa que quiere ir a Rocha, porque allí "nace el sol", interpretación personalísima, literal y trunca del lema que se aloja en el escudo de ese Departamento, ubicado en el extremo oeste de Uruguay. Con ese ingenuo y erróneo aserto Morosoli parodia el discurso nacionalista y del orgullo comarcal, puesto que el escudo de esa jurisdicción del pasí reza que "Aquí nace el sol de la patria". Aniceto, entre deslumbrado y atónito, se suma a la aventura y así salen con ese rumbo, pero nunca logran su objetivo porque, antes, la policía cree que son contrabandistas y por lo mismo se los demora unas cuantas horas en la comisaría. Cuando al cabo se los libera sin muchos miramientos, el cansancio y el susto de ese absurdo traspié los persuade de volver a su pueblo. La historia se proyecta más allá de la frustración porque, dice Tertuliano, "los viajes empiezan después que uno llega" (Morosoli, "El largo viaje de placer”, 2009: 503). En otras palabras: más que como imágenes o sumas de experiencias individuales los viajes persisten si se tornan relatos. El relato es el viaje.

Algunos ejemplos de la traducción de giros orales que escoge Faraco en portugués muestran las dificultades y el balanceo entre el dialecto, el sistema y la norma que, por lo menos, comprometen cuatro aspectos:

1) Sustantivos dialectales en función de verbos conjugados: "El Indio me cargosiaba ... y yo, nada...". Faraco traduce en la antología general: "O Índio cargoseando e eu 
nada"; luego, en el volumen: "O Índio insistindo e me dizendo que não". En los dos casos se suprimen los puntos suspensivos que, también en dos ocasiones, Morosoli emplea para mostrar las largas pausas del simulado hablante entre cada cláusula. Pero, además, la segunda traducción del pasaje utiliza el gerundio de dos verbos distintos, primero reproduce la voz rioplatense ("cargoseando"), pero en la versión final prefiere sustituirla por la forma académica ("insistindo").

2) El plano fonológico. En una ocasión, al menos, Faraco se deja llevar por las relaciones entre el sonido y las equivalencias semánticas de la paremia, recurso del que el autor uruguayo nunca abusa. Donde Morosoli escribe: "Suerte y muerte se enamoran con verte", el escritor gaúcho traduce con excelente oído: "Sorte e morte escolham seu consor$t e$ ". Morosoli acude a una frase que conforma un endecasílabo simple confiada a la rima interna con énfasis en la vocal "e" y la repetición de la figura fónica "te"; algo de esto se traslada a la lengua de llegada, y aunque el refrán no tiene exactamente el mismo sentido, permanece por asociación más en el nivel acústico que en el semántico. Todo un hallazgo.

3) El plano lexical. El traductor decide no correr muchos riesgos acercándose más a la norma en su lengua, en la que permite sólo algunas filtraciones dialectales de origen o, incluso, unas pocas palabras regionales. Un par de ejemplos de "A longa viagem de prazer":

(I) 'Pasaron la noche en una fonda 'de puchero y guiso'y mucho antes del alba partieron hacia el Chuy", se traslada al portugués como "Passaram a noite numa pensão barata e muito antes da aurora partiram para o Chuy".

(II) "Antesmente -siguió Tertuliano- las ciudades no progresaban", se vuelve "Antigamente-seguiu Tertuliano-as cidades não progrediam".

En el primer caso el traductor abole toda la potencia local del sintagma entrecomillado por Morosoli (o por sus editores, inexpertos en el uso de la itálica como marca gráfica diferencial), procedimiento que ejerce, como se dijo, para separar algunos términos del habla campera del repertorio académico. ${ }^{10}$ En el segundo caso el "antigamente", que tiene una perfecta correspondencia con la palabra castellana "antiguamente" sofoca en la elección del traductor toda la carga humorística del barbarismo "antesmente", invención difícil de registrar en otros textos de la época.

Algo similar ocurre con "Mucho campo y niún alma-respondió Aniceto", que Faraco interpreta a favor de la estandarización: "Muito campo e nenhuma alma-disse Aniceto" (El destacado me pertenece). Quedaba la posibilidad de franquear el paso a algunos rioplatenismos para evitar la creación de neologismos de dudosa eficacia y buen gusto, pero Sérgio Faraco acepta esta posibilidad en una sola ocasión: "Hermano -dijo Aniceto-, hemos hecho un lindo viaje", se traslada como "Hermano-disse Aniceto-, fizemos uma linda viagem". De haberlo querido para el primer nombre podría haber elegido un término equivalente y casi eufónico ("Meu irmão" o simplemente "irmão"); al conservar el sustantivo en castellano que cualquier lector lusohablante descodifica con facilidad,

10 En el acervo universitario que preserva los materiales de Morosoli sólo hay dos prolijas copias mecanografiadas de "El largo viaje de placer", seguramente por Raviolo cuando en 1964 publicó en libro por primera vez este relato. En esas copias el vocablo fonda aparece entrecomillado y, luego, idéntico recurso gráfico se emplea con "de puchero y guiso". En la versión impresa el editor los reunió bajo las mismas comillas. 
mantiene el tono de frontera y salva la cordial intensidad emocional de la palabra que contagia la frase, que se expande semánticamente por toda la escena.

4) Otras tensiones de la oralidad en la escritura. En ocasiones, y sin nota del traductor que advierta la decisión -algo que habitualmente Faraco prefiere no seguir en su trabajo-, disuelve la supervivencia oral en la escritura. Este aspecto tiene una enorme importancia cultural y poética. El fuertemente dialectal "El compañero", de Hombres, se clausura con este diálogo en su edición original:

-Compañero, v'ia seguir...

-Lo qué v'aser?

-A seguir... Qué v'ia hacer aquí? eh?

Y se fué no más. (Morosoli, 1932: 38).

Diez años después, Morosoli morigera su lenguaje acercándose un poco a la norma y agrega una interrogativa:

-Compañero, v'ia seguir...

-Lo qué v'hacer?

-A seguir... ¿Qué v'ia hacer aquí? ¿Eh? ¿No le parece?

Y se fue no más. (Morosoli, 1967: 31 [1942]).

Esta es la versión que se reprodujo en la antología de la que, con seguridad, Faraco tradujo el cuento. Lo hizo así, desconociendo las tres contracciones que el autor dejó vivas de la primera a la segunda edición de su libro:

-Vou embora, companheiro.

$-\mathrm{O}$ que vai fazer?

-Vou em frente. O que eu ia fazer, ficando aquí?

E foi-se. (Morosoli, 1991: 52).

También en "El largo viaje de placer" se encuentran algunos casos. Verbigracia: “Así fue, pues. Y Tertuliano estaba allí con el camión", se traduce "E ali estava Tertuliano com seu caminhão". De esa manera elige quitar el rodeo inicial y mueve al comienzo de la frase el deíctico ("alli”), que tiene un leve matiz formulario en la oralidad rioplatense.

Más delicado y atractivo es lo que sucede con una forma verbal que puede hallarse en diferentes textos y desempeña un papel muy destacado en el eje de las relaciones entre significado y significante en la prosa de Morosoli. Se trata de una expresión que, con leves permutaciones, regresa y que inaugura en el impresionante cierre del cuento "Un gaucho", publicado por primera vez en el Suplemento Dominical de El Día el 18/XI/1951. Alguien pregunta al protagonista de esta historia, al que nadie había visto nunca por esos lares, si había tratado al muerto que estaban velando, y obtiene esta contestación: "No-dijo el mozo-, pero no está lejos que fuera mi padre" (Morosoli, 2009: 377). Faraco traslada al portugués ese giro crucial para el cuento con esta fórmula: "Não-disse o moço-, mas pode ser que tenha sido meu pai" (Morosoli, 1991: 33). "No está nada lejos que te lleve...", dice en "El largo viaje de placer" el dueño del camión a su compadre. Y este, en un segmento posterior del relato apunta: "No está nada lejos que estés en lo cierto". Faraco traduce ese tan usado "no está nada lejos que te lleve" por el factible "Pode ser que te leve"; y "no está nada lejos 


\section{Conexão Letras}

que estés en lo cierto" como "Pode ser, sim, que tenhas razão". Todas sus opciones son explicativas y con ellas, en cierta medida, despoja a la frase del sesgo oral en español, aunque moderadamente esa imprescindible matriz se reintroduce con la afirmación intermedia y entrecomillado que está presente en la segunda versión.

\section{Conclusiones}

"A longa viagem de prazer" es un cuento de Morosoli y, también, por momentos se contagia de la estética de Faraco, de las ideas sobre la lengua y el habla, el sistema y la norma con las que escribe sus cuentos. Al margen del trajinado debate entre literalidad y creación en el acto traductor, es corriente que esto suceda cuando los traductores son propietarios de una obra con una realización identificable y con una poética definida antes que profesionales estrictos de la traducción. Si es que tal categoría resulta posible.

Faraco ejecuta la dulce venganza creativa del escritor-traductor, la de quien adapta a su percepción del lenguaje y el mundo el de otro escritor a quien admira, respeta y por eso mismo termina devorando. Otro que, como Morosoli, tuvo que atravesar muchas fronteras internas en un circuito de producción no muy diferente en el que se movería Faraco varias décadas más tarde. El primer y más difícil límite que Morosoli debió cruzar fue el de adoptar y fijar en su escritura expresiones de los sujetos de su medio. Con todos los recaudos ejerció el difícil arte de interpretar las palabras de su comunidad o, algo que es casi lo mismo, traducirlas.

\section{Bibliografía}

\section{Corpus}

ALEMANY, Carmen (comp.). La polémica del Meridiano intelectual de Hispanoamérica (1927). Valencia: Publicaciones de la Universidad de Alicante, 1998. [Recoge gran parte de los textos que, durante 1927 y 1928 discutieron la propuesta de Guillermo de Torre de transformar a Madrid en "meridiano intelectual de Hispanoamérica"]. ARREGUI, Mario y Sérgio FARACO. Correspondencia. Montevideo: Monte Sexto, 1990. Introducción de Martín Arregui. Sin indicación de traductor. (Ed. en portugués: Diálogos sem fronteira. Correspondencia Mario Arregui \& Sergio Faraco. Porto Alegre, LP\&M, 2009. Tradução e notas de Sergio Faraco. Introdução de Pablo Rocca. Reproduce la introducción de Martín Arregui de 1990). GARCÍA SCHLEE, Aldyr y Sérgio FARACO (comp., tradução, prólogo e notas). Para Sempre Uruguai. Porto Alegre: Instituto Estadual do Livro, 1991. [Antología general de cuentos uruguayos. Incluye "A longa viagem de prazer", de Juan José Morosoli em traducción de Sérgio Faraco].

FARACO, Sérgio. Contos completos. Porto Alegre: L\&PM, 2011. ( $3^{\mathrm{a}}$ ed. ampliada). MOROSOLI, Juan José. “Un soldado”. Original mecanografiado, seis folios, circa 1953. Colección Juan José Morosoli, Caja 6. Sección de Archivo y Documentación del Instituto de Letras (SADIL), Facultad de Humanidades y Ciencias de la Educación, Universidad de la República, Montevideo.

“El largo viaje de placer". Original mecanografiado, cinco folios. Colección Juan José Morosoli, Caja 6. Sección de Archivo y Documentación del Instituto de Letras (SADIL), Facultad de Humanidades y Ciencias de la Educación, Universidad de la República, Montevideo. 
. "El compañero". Hombres. Minas, Talleres de Ramón Trelles, 1932: 35-38.

. "El compañero". Hombres. Montevideo, Ediciones da la Banda Oriental, 1967:

27-31. Prólogo y notas de Heber Raviolo. Reproduce la reedición corregida del volumen realizada en Montevideo en 1942, con el prólogo de Francisco Espínola.

. "Los tres compañeros". Los albañiles de "Los Tapes". Montevideo/Buenos

Aires, Sociedad de Amigos del Libro Rioplatense, 1936: 87-96.

. "Cómo escribo mis cuentos". La soledad y la creación literaria. Montevideo: Edi-

ciones de la Banda Oriental, 1971: 97-102. Edición y prólogo de Heber Raviolo. [1945].

. "La novela nacional y alguno de sus problemas actuales". La soledad y la

creación literaria. Montevideo: Ediciones de la Banda Oriental, 1971: 63-74. Edición y prólogo de Heber Raviolo. [1953].

. A longa viagem de prazer. Porto Alegre, Instituto Estadual do Livro, 1991. Tra-

dução de Sérgio Faraco. Prólogo de Heber Raviolo.

. A longa viagem de prazer. Porto Alegre: LP\&M, 2009. Tradução de Sérgio Faraco. Apresentação de Léa Masina, prólogo de Heber Raviolo, posfácio de Pablo Rocca.

. Ensayo y teatro inéditos. Montevideo: Banda Oriental/Facultad de Humanidades y Ciencias de la Educación/ UdelaR, 1999. Investigación de Luis Volonté y María G. Núñez. Bibliografía crítica de la obra de Morosoli de Luis Volonté. Dirección: Pablo Rocca.

. Cuentos completos. Montevideo: Ediciones de la Banda Oriental/ Biblioteca Nacional, 2009. Edición, prólogo y notas de Heber Raviolo.

SARMIENTO, Domingo F. Ortografía, instrucción pública, 1841-1854. Buenos Aires: Ed. Luz del día, 1949. (Tomo IV de Obras Completas).

\section{Crítica y teoría}

BAJTÍN, Mijail. Teoría y estética de la novela. Madrid: Taurus, 1989. Traducción de Helena S. Kriukova y Vicente Cazcarra.

CANDIDO, Antonio. "Literatura y subdesarrollo", en América Latina en su literatura, César Fernández Moreno (coord. e introducción). México: Siglo XXI/UNESCO, 1972: 335-353.

CANDIDO, Antonio y Ángel RAMA. Un proyecto latinoamericano (Correspondencia de Ángel Rama y Antonio Candido con un anexo con la correspondencia de Gilda de Mello e Souza a Rama y textos inéditos de Candido). Montevideo, Hum/ Estuario, 2016. Edición, investigación, prólogo y notas de Pablo Rocca.

COSERIU, Eugenio. Sistema, norma y habla. In: Teoría del lenguaje y lingüística general. Cinco estudios. Madrid: Gredos, 1962: 11-113. [1953].

GROSSMAN, Rudolf. El patrimonio lingüístico extranjero en el español del Río de la Plata. Buenos Aires: Biblioteca Nacional, 2008. Estudio preliminar de Fernando Alfón.

Traducción y notas de Juan Ennis. [1926].

ROCCA, Pablo. Horacio Quiroga, el escritor y el mito (Revisiones). Montevideo: Ediciones de la Banda Oriental, 2006.

RONA, José Pedro. Dialectología general e hispanoamericana. Montevideo: Colección de Clásicos Uruguayos, Biblioteca Artigas, 2014. Prólogo de Adolfo Elizaincín.

Recebido em 21/03/2017. Aceito em 21/04/2017. 